\title{
PERAN SHOPPING ENJOYMENT MEMEDIASI PENGARUH HEDONIC MOTIVATION TERHADAP IMPULSE BUYING
}

\section{Putu Cindy Clarista Darmaningrum ${ }^{1}$ I Putu Gde Sukaatmadja ${ }^{2}$}

\author{
${ }^{1,2}$ Fakultas Ekonomi dan Bisnis Universitas Udayana (Unud), Bali, Indonesia \\ E-mail: cindy.clarista@gmail.com
}

\begin{abstract}
ABSTRAK
Tujuan penelitian ini adalah untuk menjelaskan peran shopping enjoyment memediasi hedonic motivation terhadap impulse buying. Penelitian ini dilakukan pada konsumen Stradivarius Beachwalk. Ukuran sampel yang digunakan dalam penelitian ini adalah sebanyak 105 responden, dengan metode purposive sampling. Pengumpulan data dilakukan melalui kuesioner, wawancara, dan observasi. Teknik analisis yang digunakan adalah analisis jalur (path analysis). Berdasarkan hasil penelitian, ditemukan shopping enjoyment mampu memediasi secara parsial hedonic motivation terhadap impulse buying. Selanjutnyahedonic motivationberpengaruh positif dan signifikan terhadap impulse buying;hedonic motivation berpengaruh positif dan signifikan terhadap shopping enjoyment;shopping enjoymentberpengaruh positif dan signifikan terhadap impulse buying; serta shopping enjoyment berperan sebagai variabel mediasi antara hedonic motivation dan impulse buying.Berdasarkan temuan penelitian ini disarankan bahwa hedonic motivation dan shopping enjoyment yang baik sangat mempengaruhi impulse buyingkonsumen di Stradivarius Beachwalk.

Kata kunci:hedonic motivation, shopping enjoyment, impulse buying
\end{abstract}

\begin{abstract}
The purpose of this study is to explain the role of enjoyment shopping mediating hedonic motivation towards impulse buying. This research was conducted at consumers of Stradivarius Beachwalk. The measure of samples used in this study were 105 respondents, with a purposive sampling method. Data collection is done through questionnaires, interviews, and observations. The analysis technique used is path analysis. Based on the results, it was found that shopping enjoyment is able to mediate partially hedonic motivation towards impulse buying. Furthermore, hedonic motivation has a positive and significant effect on impulse buying; hedonic motivation has a positive and significant effect on shopping enjoyment; shopping enjoyment has a positive and significant effect on impulse buying; and shopping enjoyment acts as a mediating variable between hedonic motivation and impulse buying. Based on the findings of this study suggested that hedonic motivation and good shopping enjoyment greatly affect consumer impulse buying at Stradivarius Beachwalk.

Keywords: hedonic motivation, shopping enjoyment, impulse buying
\end{abstract}




\section{PENDAHULUAN}

Perkembangan bisnis pada era globalisasi ini semakin pesat. Banyak pengusaha membuka bisnis ritel menyebabkan persaingan yang terjadi berkembang pesat seiring dengan perkembangan masyarakat dan teknologi semakin maju. Globalisasi merupakan faktor utama terciptanya permintaan dengan meningkatnya permintaan akan barang dan jasa ritel (Setyningrum et al., 2016). Hal inilah yang mendorong para pelaku bisnis untuk bisa lebih proaktif dan berinovasi baik dalam memberikan produk maupun pelayanan yang prima untuk mendapatkan keunggulan bersaing dalam rangka memenangkan pangsa pasar (Temaja et al., 2015).

Menurut marketing.co.id dalam periode beberapa tahun terakhir, dari tahun 2007-2012, jumlah gerai ritel modern di Indonesia mengalami pertumbuhan ratarata 17,57 persen per tahun. Globalisasi ekonomi yang terjadi saat ini membuat persaingan yang ketat antara produk dalam negeri dengan produk luar negeri (Mirandha dan Iskandarsyah, 2017). Menurut Setyningrum et al. (2016) banyaknya persaingan disektor ritel yang terjadi saat ini menjadikan banyak peritel asing yang masuk dengan mudah pada pasar domestik. Mudahnya peritel asing untuk masuk, maka dimanfaatkan oleh peritel asing sebagai peluang bisnis. Menurut cnbcindonesia.com banyak masyarakat Indonesia yang lebih suka membeli busana hingga aksesoris dari brand asing. Enam puluh persen konsumen Indonesia lebih suka membeli berbagai produk luar negeri dibandingkan buatan Indonesia. 
Perkembangan bisnis ritel di Indonesia dapat dikatakan menjadi sebuah faktor yang mendorong berkembangnya trend fashion di Indonesia. Dilihat dari banyaknya permintaan di pasar akan trend fashion yang sedang berkembang serta mendominasinya gerai fashion yang terdapat dalam bisnis ritel seperti mal juga menunjukkan perkembangan fashion kian meningkat di Indonesia (Kinasih dan Jatra, 2018). Berdasarkan data dari survei dari Badan Ekonomi Kreatif dan Badan Pusat Statistik (BPS) merilis bahwa sektor Ekonomi Kreatif menyumbang 7,38 persen terhadap total perekonomian nasional tahun 2016 dan sektor fashion berkontribusi sebanyak 18,15 persen atau nomor dua setelah kuliner (wartakota.tribunnews.com).

Hal ini menunjukkan bahwa masyarakat Indonesia sudah sangat menyadari untuk berpenampilan menarik dan stylist mengikuti perkembangan trendfashion yang sedang berkembang. Seiring dengan kebutuhan konsumen yang semakin bervariasi, peluang bagi para pelaku bisnis terutama dalam bidang fashion telah mengalami peningkatan (Wiguna dan Nurcahya, 2013). Fashion selalu dikaitkan dengan mode, cara pakaian yang mengikuti jaman dan up to date. Gaya hidup seseorang yang megikuti fashion atau mode mengaplikasikan dengan cara dalam mengenakan pakaian, aksesoris, atau bahkan dalam bentuk model rambut hingga make up (Wibawa dan Geodita, 2018). Perubahan jaman pada fashion yang berganti-ganti hampir di setiap bulan, maka konsumen yang selalu mengikuti perubahan jaman tersebut akan terlihat unggul baik dalam berpakaian yang nanti akan menegaskan identitas individu tersebut dalam lingkungan sosialnya (Deviana dan Giantari, 2016). Kebutuhan masyarakat akan pakaian sangat besar, itu bisa 
dilihat dari jumlah permintaan disetiap tahunnya, setiap masyarakat mempunyai pertimbangan dalam memilih pakaian yang diinginkannya, karena setiap masyarakat mempunyai persepsi yang berbeda-beda dalam melakukan pengambilan keputusan dalam membeli produk pakaian (Desman et al., 2018).

Salah satu merek pakaianadalah Stradivarius yang telah lama dikenal oleh sebagian besar masyarakat di Indonesia. Dalam memasarkan produknya, perusahaan selalu berusaha untuk menjaga kualitas dan mutu produknya sehingga produk pakaian ini dapat diterima dengan baik oleh masyarakat, selain itu merek Stradivarius terus berusaha agar tetap unggul di antara para pesaingnya yang menawarkan produk sejenis. Perkembangan industri fashion di Indonesia semakin berkembang dilihat dari brand lokal maupun internasional yang masuk ke Indonesia. Salah satu nya, fashion brand international terdapat Zara, Stradivarius, Mango, Topshop, Pull \& Bear, dan Berskha. Brand tersebut saat ini telah memiliki gerai penjualan di Indonesia. Berikut ini adalah daftar fashion brand internasional yang masuk ke Indonesia beserta dengan jumlah gerai yang tersebar di Indonesia.

Tabel 1.

Jumlah Gerai FashionBrand Internasional di Indonesia

\begin{tabular}{|c|c|c|}
\hline & Brand & Jumlah Gerai \\
\hline & Zara & 14 \\
\hline & Stradivarius & 11 \\
\hline & Mango & 11 \\
\hline & Pull\&Bear & 10 \\
\hline & Topshop & 8 \\
\hline & Berskha & 7 \\
\hline
\end{tabular}

Sumber: www.map.co.id, 2018

Berdasarkan Tabel 1 menunjukan bahwa brand Stradivarius berada di peringkat ke 2 jumlah gerai brand terbanyak di Indonesia, sedangkan yang berada 
Putu Cindy Clarista Darmaningrum, Peran Shopping Enjoyment...

pada peringkat pertama yaitu Zara. Stradivarius merupakan fashion brand Spanyol yang memproduksi model pakaian updateto date diperuntukkan untuk perempuan (www.bitebrands.co). Stradivarius menjadi salah satu brand yang tidak pernah sepi pembeli. Saat ini, Stradivarius memiliki 6.300 toko yang terbagi di 87 negara, termasuk sejumlah toko di pusat perbelanjaan terkemuka di Indonesia, yaitu sebayak 11 store di Jakarta, Bandung, Bali, dan Surabaya (dailymail.com). Stradivarius mengambil pasar ditunjukan untuk perempuan yang berusia 17 sampai 35 tahun. Stradivarius menjual pakaian, sepatu, tas, perhiasan, dan aksesoris dengan harga yang lebih rendah dari pada pesaing brand lainnya seperti Zara. Stradivarius mengutamakan model-model terbaru disetiap produk yang dikeluarkan, dengan mengikuti selera pelangan, memperhatikan trend saat ini, dan menggunakan cara menampilkan desain pakaian yang baru melalui fashion leaders pada social media (businessoffashion.com).

Beachwalk merupakan salah satu mal yang memiliki gerai fashion brand internasional yang termasuk lengkap dan merupakan satu-satunya mal yang memiliki gerai Stradivarius di Bali. Suasana toko yang nyaman dan model pakaian yang selalu mengikuti selera pasar, membuat Stradivarius menjadi salah satu pilihan toko yang tepat untuk berbelanja.

Ketika berbelanja, seseorang akan memilki emosi positif ingin membeli produk tersebut tanpa perencanaan sebelumnya berupa catatan daftar belanja (Kosyu et al., 2014). Rasa ketergantungan terhadap dunia fashion yang selalu berubah-ubah, membuat sebagian masyarakat menjadi hedon dan termotivasi untuk selalu memperbaharui gaya fashion sehari-hari dengan melakukan 
pembelian yang tidak terencana sebelumnya (Sampurno dan Winarso, 2015). Perilaku impulse buying cenderung mendominasi perilaku pembelian yang dilakukan oleh konsumen pada saat ini (Naentiana dan Setiawan, 2014). Impulse buying merupakan perilaku orang yang tidak merencanakan sesuatu dalam berbelanja (Purnomo dan Riani, 2018). Konsumen yang sangat impulsif cenderung tidak memikirkan sesuatu, gampang tertarik terhadap sesuatu, dan menginginkan kepuasan segera (Deviana dan Giantari, 2016).

Reaksi impulsif merupakan kecenderungan konsumen untuk membeli secara spontan, mendadak, segera dan cenderung terjadi secara tiba-tiba. Impulse buying merupakan sifat perseorangan yang muncul sebagai respon atas stimuli lingkungan. Reaksi impulsif yang dirasakan oleh seseorang sulit membatasi perilaku dan seringkali konsisten dengan pembelian impulsif di dalam konteks berbelanja (Lestari, 2015).

Beberapa faktor yang menjadi alasan mengapa seseorang terdorong untuk melakukan impulse buying di antaranya adalah karena faktor internal dan faktor eksternal. Faktor internal yang ada pada diri seseorang yaitu pada suasana hati dan kebiasaan mereka berbelanja apakah di dorong sifat hedonis atau tidak. Faktor eksternal yang mempengaruhi impulse buying berasal dari stimulus yang diberikan oleh pihak peritel yaitu pada lingkungan toko dan promosi yang ditawarkan toko (Manggiasih et al., 2015). Saad dan Metawie (2015), keputusan impulse buying memiliki beberapa faktor diantaranya kepribadian, harga diri, kenikmatan, dan impulsivity. 
Salman (2014) menyebutkan karakteristik produk bukan satu-satunya faktor yang menyebabkan pembelian, karakteristik konsumen juga memiliki peran penting dalam hal pembelian. Menurut Beatty dan Ferrell (1998) dalam Purnasari dan Rastini (2018), shopping enjoyment adalah keadaan yang mendorong impulse buying. Studi ini juga menyimpulkan bahwa seseorang yang menikmati berbelanja akan meningkatkan impulse buying. Saat ini kebanyakan konsumen lebih berorientasi rekreasi yang mementingkan aspek kesenangan, kenikmatan, dan hiburan saat berbelanja (Oktafiana dan Indriastuti, 2018). Penelitian yang dilakukan Amel et al. (2014) menyatakan dalam penelitian yang dilakukan bahwa keinginan hedonis mempengaruhi shopping enjoyment. Shopping enjoyment diciptakan dari pengalaman belanja yang menyenangkan, bukan dari penyelesaian aktivitas berbelanja (Tambunan dan Handayani, 2017).

Belanja yang telah menjadi kenikmatan tersendiri bagi sebagian orang, menjadi salah satu pendorong terjadinya hedonic motivation (Utami, 2010). Motivasi belanja konsumen merupakan dorongan untuk berbelanja yang berasal dari dalam diri konsumen dengan tujuan untuk memenuhi kepuasan. Salah satu motivasi yang didorong oleh emosi mencari kesenangan semata yaitu hedonic motivation (Tjantoko, 2015). Konsumen menganggap berbelanja lebih dari memperoleh produk tetapi sebagai pengalaman yang menghibur (Amel et al., 2014). Sebagian konsumen berbelanja hanya untuk memenuhi kebutuhan kepribadian hedonisnya (Saad dan Metawie, 2015). Konsumen yang cenderung memiliki sifat hedonis akan pergi berbelanja saat memiliki waktu luang atau saat bersenang-senang (Oktafiana dan Indriastuti, 2018). Lestari (2015) menyatakan 
bahwa hedonic motivation berkaitan dengan emosional konsumen sehinngga ketika berbelanja konsumen benar-benar merasakan sesuatu seperti senang, benci, marah, ataupun merasa bahwa berbelanja merupakan suatu petualangan. Hedonic motivation akan tercipta dengan adanya gairah berbelanja seseorang yang mudah terpengaruh model terbaru dan berbelanja menjadi gaya hidup seseorang untuk memenuhi kebutuhan sehari-hari (Sampurno dan Winarso, 2015). Keputusan konsumen untuk melakukan pembelian dengan hedonic motivation beralasan karena pencarian kesenangan dari mengkonsumsi produk tersebut (Paramitha, 2014).

\section{Tabel 2.}

Tabel Pra Survei

\begin{tabular}{clccc}
\hline Variabel & \multicolumn{1}{c}{ Pernyataan } & \multicolumn{1}{c}{ Setuju } & \multicolumn{1}{c}{$\begin{array}{c}\text { Tidak } \\
\text { Setuju }\end{array}$} & Responden \\
Impulse Buying & $\begin{array}{l}\text { Saya melakukan pembelian tidak } \\
\text { terencana (impulse buying) di } \\
\text { Stradivarius karena terdapat banyaknya } \\
\text { penawaran yang menarik }\end{array}$ & 25 & 5 & 30 \\
$\begin{array}{c}\text { Shopping } \\
\text { enjoyment }\end{array}$ & $\begin{array}{l}\text { Saya merasa saat berbelanja di } \\
\text { Stradivarius suasana toko terasa } \\
\text { nyaman dan terasa nikmat mencari } \\
\text { produk }\end{array}$ & 22 & 9 & 30 \\
Hedonic & $\begin{array}{l}\text { Saya berbelanja di Stradivarius karena } \\
\text { harga lebih terjangkau dibandingkan } \\
\text { brand lainnya dan mengikuti fashion } \\
\text { trend }\end{array}$ & 20 & 7 & 30 \\
& & & \\
& & & \\
\end{tabular}

Sumber: Data diolah, 2018

Beranjak dari hal tersebut untuk mengetahui seberapa besar perilaku pembelian tidak terencana konsumen di Stradivarius, maka dilakukan penelitian dengan menggunakan metode pra survei dengan menyebarkan kuisioner sementara kepada 30 responden. Berdasarkan hasil pra survei, 72 persen responden melakukan pembelian tidak terencana (impulse buying) karena terdapat penawaran yang menarik yang ditawarkan oleh Stradivarius, sebanyak 66 persen responden merasa bahwa berbelanja di Stradivarius suasana toko terasa nyaman 
dan terasa nikmat mencari produk. Kemudian 60 persen responden berbelanja di Stradivarius karena harga yang di tawarkan lebih terjangkau dibandingkan brand lainnya dan mengikuti fashion trend.

Amel et al. (2014) mengungkapkan bahwa hedonic motivation berpengaruh positif signifikan terhadap impulse buying. Hasil yang bertentangan ditemukan oleh Rohman (2009) menemukan bahwa belanja hedonik tidak mempengaruhi pembelian impulsif. Saad dan Metawie (2015) yang menyatakan bahwa shopping enjoyment berpengaruh positif signifikan terhadap impulse buying. Hasil yang bertentangan ditemukan oleh Rahayu (2017) bahwa shopping enjoyment tidak berpengaruh terhadap impulse buying.

Konus et al. (2008) menyatakan bahwa hedonic motivation berhubungan dengan shopping enjoyment. Kim dan Youn (2008) menyatakan bahwa hedonic motivation berpengaruh positif signifikan terhadap shopping enjoyment. Amel et al. (2014) menyatakan bahwa hedonic motivation berpengaruh positif terhadap shopping enjoyment. Berdasarkan hal tersebut hipotesis yang dapat dikembangkan dalam penelitian ini adalah:

$\mathrm{H}_{1}$ : Hedonic motivation berpengaruh positif signifikan terhadap shopping enjoyment

Amel et al. (2014) menyatakan bahwa hedonic motivation berpengaruh signifikan terhadap impulse buying. Hal ini didukung oleh Kosyu et al. (2014), terdapat pengaruh langsung yang signifikan dari hedonic motivation terhadap impulse buying. Dalam penelitian Mamuaya dan Aditya (2018) menyatakan bahwa hedonic motivation berpengaruh positif signifikan terhadap impulse 
buying. Suhartini et al. (2016) semakin konsumen merasakan hedonic motivation yang baik, maka akan menyebabkan tingkat impulse buying yang semakin tinggi. Namun penelitian yang dilakukan oleh Rohman (2009) menemukan bahwa belanja hedonik tidak mempengaruhi pembelian impulsif. Berdasarkan hal tersebut hipotesis yang dapat dikembangkan dalam penelitian ini adalah:

$\mathrm{H}_{2}$ : Hedonic Motivation berpengaruh positif signifikan terhadap impulse buying

Gunadhi (2012) menyatkan bahwa shopping enjoyment berpengaruh signifikan terhadap impulse buying. Amel et al. (2014) berpendapat bahwa shopping enjoyment berpengaruh positif signifikan terhadap impulse buying. Badgaiyan dan Anshul (2014) menyatakan bahwa shopping enjoyment berpengaruh positif signifikan terhadap impulse buying. Hal ini didukung oleh pendapat Saad dan Metawie (2015) yang menyatakan bahwa shopping enjoyment berpengaruh positif signifikan terhadap impulse buying. Purnasari dan Rastini (2018) menyatakan bahwa shopping enjoyment berpengaruh positif signifikan terhadap impulse buying. Bertentangan dengan penelitian Rahayu (2017) menyatakan bahwa shopping enjoyment tidak berpengaruh positif signifikan terhadap impulse buying. Berdasarkan hal tersebut hipotesis yang dapat dikembangkan dalam penelitian ini adalah:

$\mathrm{H}_{3}$ : Shopping Enjoyment berpengaruh positif signifikan terhadap impulse buying

Mengacu pada hipotesis-hipotesis yang telah ditarik dengan menggunakan penelitian-penelitian sebelumnya sebagai acuan dalam penarikan hipotesis, maka dapat diindikasikan terdapatnya hubungan yang saling mempengaruhi diantara 
variabel hedonic motivation, shopping enjoyment, dan impulse buying. Kim dan Youn (2008) menyatakan bahwa hedonic motivation berpengaruh positif signifikan terhadap shopping enjoyment. Andryansyah dan Zainul (2018) menyatakan hedonic motives memiliki pengaruh signifikan terhadap impulse buying. Mohan et al. (2013) yang menyatakan bahwa shopping enjoyment berpengaruh positif signifikan terhadap impulse buying. Amel et al. (2014) menyatakan bahwa hedonic motivation berpengaruh positif dan signifikan terhadap impulse buying dengan mediasi shopping enjoyment. Berdasarkan hal tersebut hipotesis yang dapat dikembangkan dalam penelitian ini adalah:

$\mathrm{H}_{4}$ : Hedonic motivation berpengaruh positif dan signifikan terhadap impulse buying dengan mediasi shopping enjoyment.

\section{METODE PENELITIAN}

Lokasi penelitian ini dilakukan di Kuta, Kabupaten Badung, Bali. Penelitian dilakukan di Stradivarius Beachwalk Mall Kuta Jalan Pantai Kuta, Kabupaten Badung Bali. Lokasi ini dipilih karena Beachwalk merupakan salah satu mal terbesar di Bali yang hanya memiliki gerai Stradivarius.

Obyek penelitian yang digunakan dalam penelitian kali ini adalah impulse buying yang terjadi di outlet Stradivarius yang dipengaruhi hedonic motivation dan shopping enjoyment. Hal ini disebabkan bahwa dari penelitian terdahulu menyatakan bahwa hedonic motivation berpegaruh terhadap impulse buying dimediasi shopping enjoyment (Amel et al., 2014). Namun penelitian yang dilakukan oleh Rohman (2009) menyatakan bahwa hedonic motivation tidak 
berpengaruh signifikan terhadap impulse buying dan Rahayu (2017) menyatakan bahwa shopping enjoyment tidak berpengaruh signifikan terhadap impulse buying.

Populasi dalam penelitian ini adalah konsumen Stradivarius di Kabupaten Badung yang jumlahnya tidak dapat dihitung secara pasti. Dalam penelitian ini, metode penentuan sampel yang digunakan yaitu non-probability sampling yaitu teknik pengambilan sampel yang tidak memberi peluang/ kesempatan yang sama bagi setiap unsur atau anggota populasi untuk dipilih menjadi sampel.

Teknik analisis yang digunakan dalam penelitian ini adalah teknik analisis jalur (path analysis).

Persamaan Sub-struktural 1

$$
Y_{1}=\beta_{1} X+e
$$

Persamaan Sub-struktural 2

$$
Y_{2}=\beta_{2} X+\beta_{2} Y_{1}+e \beta
$$

Keterangan :

$$
\begin{array}{ll}
\mathrm{Y}_{2} & =\text { impulse buying } \\
\mathrm{X} & =\text { hedonic motivation } \\
\mathrm{Y}_{1} & =\text { shopping enjoyment } \\
\beta_{2} & =\text { koefisien regresi variabel } \\
\varepsilon & =\text { error }
\end{array}
$$

Pengaruh langsung (dirrect effect)

Pengaruh variabel $(\mathrm{X})$ terhadap $\left(\mathrm{Y}_{2}\right)$

$$
Y_{2}=p_{2} x+\varepsilon_{2}
$$

Pengaruh variabel $(\mathrm{X})$ terhadap $\left(\mathrm{Y}_{1}\right)$

$$
Y_{1}=p_{1} x+\varepsilon_{1}
$$

Pengaruh variabel $\left(\mathrm{Y}_{1}\right)$ terhadap $\left(\mathrm{Y}_{2}\right)$ 


$$
Y_{2}=p_{2} y_{1} X+\varepsilon_{2}
$$

Pengaruh variabel $(\mathrm{X})$ terhadap $\left(\mathrm{Y}_{2}\right)$ dengan $\left(\mathrm{Y}_{1}\right)$ sebagai variabel perantara :

$$
Y_{2}=\left(p_{2} x\right) x\left(p_{2} y_{1} Y_{1}\right)+\varepsilon_{1}
$$

Pengaruh total (total effect)

Total pengaruh variabel $\mathrm{X}$ terhadap $\mathrm{Y}_{2}$ melalui $\mathrm{Y}_{1}$ dirumuskan sebagai berikut :

$$
Y_{2}=p_{2} x+\left(p_{1} x\right) x\left(p_{2} y_{1} Y_{1}\right)+\varepsilon_{1}
$$

Keterangan :

$$
\begin{aligned}
& \mathrm{Y}_{2} \quad=\text { impulse buying } \\
& \mathrm{X}=\text { hedonic motivation } \\
& \mathrm{Y}_{1} \quad=\text { shopping enjoyment } \\
& \rho y 1 \mathrm{x}, \rho \mathrm{y} 2 \mathrm{x}, \rho \mathrm{y} 2 \mathrm{y} 1=\text { koefisien garis regresi } \\
& \varepsilon_{1}(\text { error } 1) \quad=\text { anak panah } \varepsilon_{1} \text { yang menunjukan jumlah }
\end{aligned}
$$

$$
\left(\varepsilon_{1}=\sqrt{1}-R^{2}\right)
$$

$\varepsilon_{2}($ error 2$)=$ anak panah $\varepsilon_{2}$ yang menunjukkan jumlah varian impulse buying yang tidak dijelaskan oleh hedonic motivation.

$$
\left(\varepsilon_{2}=\sqrt{1}-R^{2}\right)
$$

\section{HASIL DAN PEMBAHASAN}

Menurut pengelompokan usia, mayoritas responden berusia 18-24 Tahun sebanyak 55,2 persen, lalu responden berusia 25- 29 tahun sebanyak 31,4 persen dan responden diatas 30 tahun sebanyak 13,3 persen. Dilihat dari jenis kelamin responden, wanita mendominasi yaitu sebanyak 75,2 persen dan pria sebanyak 24,7 persen. 
Responden yang memiliki pendidikan terakhir SMA/Sederajat mendapatkan angka tertinggi yaitu sebanyak 56,1 persen diikuti S1 sebanyak 28,5 persen, Diploma sebanyak 13,3 persen, dan S2 sebanyak 1,9 persen. Data tersebut menunjukan bahwa konsumen Stradivarius telah minimal pendidikan SMA/Sederajat. Hal ini berkaitan dengan tingkat pemahaman akan hedonic motivation dan shopping enjoyment yang nantinya akan dapat menimbulkan impulse buying yang terjadidi Stradivarius Beachwalk.

Responden yang memiliki status pekerjaan sebagai pelajar atau mahasiswa/i memiliki angka tertinggi yaitu sebesar 53,3 persen diikuti karyawan swasta 21,9 persen, wiraswasta 21,9 persen, dan Pegawai Negeri Sipil (PNS) 2,8 persen. Mayoritas responden memilih berbelanja di Stradivarius karena memiliki keunggulan diantaranya yaitu banyaknya produk baru yang dikeluarkan oleh pihak Stradivarius yang selalu di minati oleh konsumennya dan kenyamanan berbelanja yang di rasakan di Stradivarius.

Perhitungan koefisien path dilakukan dengan analisis regresi melalui software SPSS 18.0 for Windows, diperoleh hasil yang ditunjukan pada Tabel 3.

Tabel 3.

Hasil Analisis Jalur Persamaan Regresi 1

\begin{tabular}{|c|c|c|c|c|c|}
\hline \multirow[t]{2}{*}{ Model } & \multicolumn{2}{|c|}{$\begin{array}{c}\text { Unstandardized } \\
\text { Coefficients }\end{array}$} & \multirow{2}{*}{$\begin{array}{c}\text { Standardized } \\
\text { Coefficients } \\
\text { Beta } \\
\end{array}$} & \multirow[t]{2}{*}{$\mathbf{t}_{\text {hitung }}$} & \multirow[t]{2}{*}{ Sig. } \\
\hline & $\boldsymbol{B}$ & Std.Error & & & \\
\hline 1 (Constant) & 1,684 & 0,887 & & 1,898 & 0,060 \\
\hline Hedonic Motivation & 0,921 & 0,044 & 0,901 & 21,061 & 0,000 \\
\hline $\mathrm{R}_{1}$ Square & & & & & 0,812 \\
\hline F Statistik & & & & & 443,577 \\
\hline Sig F & & & & & 0,000 \\
\hline
\end{tabular}

Sumber:Data diolah, 2018

Berdasarkan hasil analisis jalur substruktur 1 seperti yang disajikan pada

Tabel 3, maka persamaan strukturalnya adalah sebagai berikut : 


$$
\begin{aligned}
& \mathrm{Y}_{1}=\beta_{1} \mathrm{X}+\varepsilon_{1} \ldots \\
& \mathrm{Y}_{1}=0,901 \mathrm{X}+\varepsilon_{1}
\end{aligned}
$$

Nilai $\beta_{1}$ adalah sebesar 0,901 memiliki arti bahwa Hedonic Motivation berpengaruh positif terhadap Shopping Enjoyment, dengan kata lain jika Hedonic Motivation meningkat maka akan mengakibatkan peningkatan pada Shopping Enjoymentdi Stradivariussebesar 0,901.

Berdasarkan hasil analisis jalur substruktur 2 seperti yang disajikan pada Tabel 4, maka persamaan strukturalnya adalah sebagai berikut :

$$
\begin{aligned}
& \mathrm{Y}_{2}=\beta_{2} \mathrm{X}+\beta_{3} \mathrm{Y}_{1}+\varepsilon_{2} \ldots \ldots \ldots \\
& \mathrm{Y}_{2}=0,360 \mathrm{X}+0,377 \mathrm{Y}_{1}+\varepsilon_{2}
\end{aligned}
$$

Tabel 4.

Hasil Analisis Jalur Persamaan Regresi 2

\begin{tabular}{lccccc}
\hline \multicolumn{1}{c}{ Model } & \multicolumn{2}{c}{$\begin{array}{c}\text { Unstandardized } \\
\text { Coefficients }\end{array}$} & $\begin{array}{c}\text { Standardized } \\
\text { Coefficients } \\
\text { Beta }\end{array}$ & $\mathbf{t}_{\text {hitung }}$ & Sig. \\
& $\boldsymbol{B}$ & Std.Error & & \\
\hline $1 \quad$ Constant) & 4,448 & 1,472 & & 3,023 & 0,003 \\
Hedonic Motivation & 0,373 & 0,164 & 0,360 & 2,271 & 0,025 \\
Shopping Enjoyment & 0,382 & 0,161 & 0,377 & 2,378 & 0,019 \\
$K_{2}$ Square & & & & & 0,517 \\
F Statistik & & & & & 54,508 \\
Sig F & & & & & 0,000 \\
\hline
\end{tabular}

Sumber : Data diolah, 2018

Nilai $\beta_{2}$ adalah sebesar 0,360 memiliki arti bahwa hedonic motivation berpengaruh positif terhadap impulse buying, dengan kata lain jika faktor hedonic motivation meningkat maka akan mengakibatkan peningkatan pada impulse buying di Stradivarius sebesar 0,360.

Nilai $\beta_{3}$ adalah sebesar 0,377 memiliki arti bahwa shopping enjoyment berpengaruh positif terhadap impulse buying, dengan kata lain jika shopping enjoyment meningkat maka akan terjadi peningkatan impulse buying di Stradivarius sebesar 0,377 . 
Berdasarkan model substruktur 1 dan substruktur 2, maka dapat disusun model diagram jalur akhir. Sebelum menyusun model diagram jalur akhir, terlebih dahulu dihitung nilai standar eror sebagai berikut:

$$
\begin{aligned}
& \mathrm{Pe}_{\mathrm{i}}=\sqrt{1-\mathrm{R}_{1}{ }^{2}} \ldots \ldots \ldots \ldots \ldots \ldots \ldots \ldots \ldots \ldots \ldots \ldots \\
& \mathrm{Pe}_{1}=\sqrt{1-R_{1}{ }^{2}}=\sqrt{1-0,812}=0,433 \\
& \mathrm{Pe}_{2}=\sqrt{1-R_{2}{ }^{2}}=\sqrt{1-0,517}=0,694
\end{aligned}
$$

Berdasarkan perhitungan pengaruh error $\left(\mathrm{Pe}_{1}\right)$, didapatkan hasil pengaruh error $\left(\mathrm{Pe}_{1}\right)$ sebesar 0,433dan pengaruh error $\left(\mathrm{Pe}_{2}\right)$ sebesar 0,694. Hasil koefisien determinasi total adalah sebagai berikut:

$$
\begin{aligned}
\mathrm{R}_{\mathrm{m}}^{2} & =1-\left(\mathrm{Pe}_{1}\right)^{2}\left(\mathrm{Pe}_{2}\right)^{2} \\
& =1-(0,433)^{2}(0,694)^{2} \\
& =1-(0,187)(0,481) \\
& =1-0,089=0,911
\end{aligned}
$$

Nilai determinasi total sebesar 0,911 mempunyai arti bahwa sebesar 91 persen variasi impulse buyingdipengaruhi oleh variasi hedonic motivation dan shopping enjoyment, sedangkan sisanya sebesar 9 persen dijelaskan oleh faktor lain yang tidak dimasukkan ke dalam model.

Berdasarkan hasil analisis pengaruh hedonic motivation terhadap shopping enjoyment diperoleh nilai Sig. t sebesar 0,000 dengan nilai koefisien beta 0,901. Nilai Sig. t 0,000 $<0,05$ mengindikasikan bahwa $\mathrm{H}_{0}$ ditolak dan $\mathrm{H}_{1}$ diterima. Hasil ini mempunyai arti bahwa hedonic motivationberpengaruh positif dan signifikan terhadapshopping enjoyment. 
Berdasarkan hasil analisis pengaruh hedonic motivationterhadap impulse buying diperoleh nilai Sig. t sebesar 0,025 dengan nilai koefisien beta 0,360. Nilai Sig. t $0,025<0,05$ mengindikasikan bahwa $\mathrm{H}_{0}$ ditolak dan $\mathrm{H}_{1}$ diterima. Hasil ini mempunyai arti bahwa hedonic motivationberpengaruh positif dan signifikan terhadap impulse buying.

Berdasarkan hasil analisis pengaruh shopping enjoyment terhadap impulse buying diperoleh nilai Sig. t sebesar 0,019 dengan nilai koefisien beta 0,377. Nilai Sig. t 0,019<0,05 mengindikasikan bahwa $\mathrm{H}_{0}$ ditolak dan $\mathrm{H}_{1}$ diterima. Hasil ini mempunyai arti bahwa shopping enjoymentberpengaruh positif dan signifikan terhadap impulse buying.

Hasil koefisien jalur 0,433 sis penelitian dapat digambarkan pada Gambar 1.

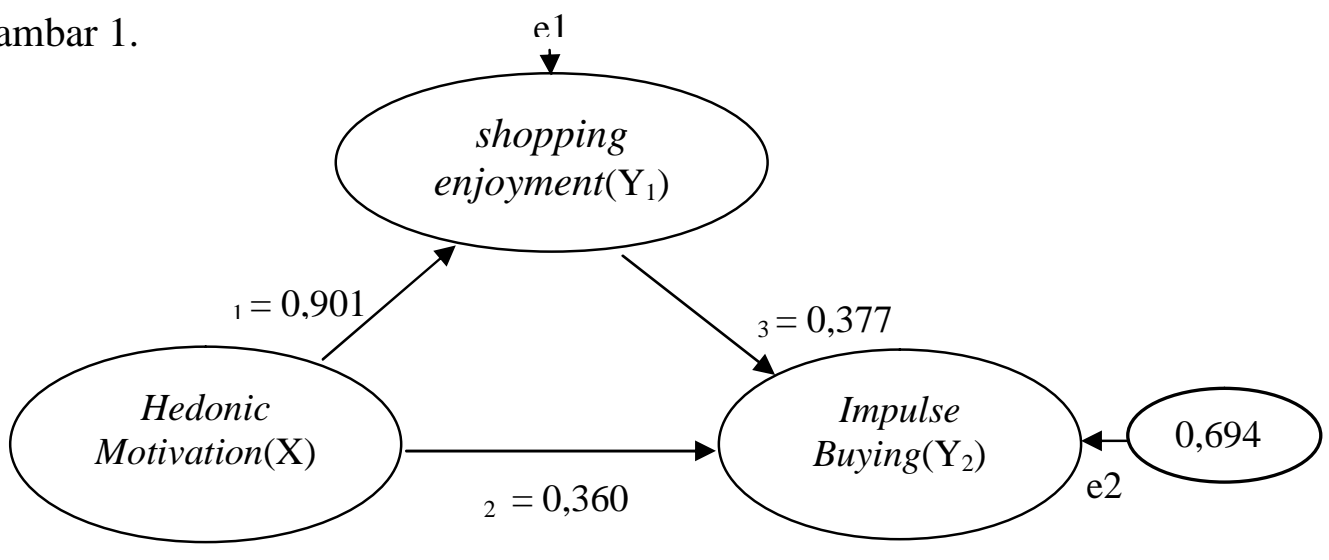

\section{Gambar 1. Validasi Model Diagram Jalur Akhir}

Menurut Putri (2016) jika hasil koefisien jalur pada $\beta_{1}$ dan $\beta_{3}$ signifikan sedangkan $\beta_{2}$ tidak signifikan maka dapat dikatakan sebagai mediasi bersifat 
penuh (complete mediation). Jika hasil koefisien jalur pada $\beta_{1}$ dan $\beta_{3}$ signifikan sedangkan $\beta_{2}$ signifikan, dimana nilai koefisien $\beta_{2}$ lebih kecil daripada nilai koefisien dari model tanpa adanya variabel mediasi, maka dapat dikatakan sebagai mediasi parsial (partial mediation). Jika hasil koefisien jalur pada $\beta_{1}$ dan $\beta_{3}$ signifikan sedangkan $\beta_{2}$ signifikan, dimana nilai koefisien $\beta_{2}$ hampir sama dengan nilai koefisien dari model tanpa adanya variabel mediasi, maka disimpulkan bukan sebagai variabel mediasi. Jika salah satu dari nilai koefisien jalur $\beta_{1}$ atau $\beta_{3}$ tidak signifikan, maka disimpulkan bukan sebagai variabel mediasi. Berdasarkan model diagram jalur pada 1 dapat diketahui bahwa besarnya pengaruh langsunghedonic motivation terhadap shopping enjoyment $\left(\beta_{1}\right)$ sebesar 0,901 dengan nilai signifikansi 0,000 (signifikan), kemudian pengaruh shopping enjoyment terhadap impulse buying $\left(\beta_{3}\right)$ sebesar 0,377 dengan nilai signifikansi 0,019 (signifikan), dan hedonic motivation terhadap impulse buying $\left(\beta_{2}\right)$ sebesar 0,360 dengan nilai signifikansi 0,025 (signifikan). Oleh karena nilai $\beta_{1}$ dan $\beta_{3}$ signifikan serta $\beta_{2}$ juga signifikan, koefisien dari pengaruh langsung hedonic motivation terhadap impulse buying $\left(\beta_{2}\right)$ sebesar 0,360 lebih kecil dari pengaruh tidak langsung hedonic motivation terhadap impulse buying $(0,901 \times 0,377=$ 0,699), maka shopping enjoyment dikatakan sebagai variabel mediasi parsial (partial mediation).Perhitungan pengaruh antar variabel terdapat dalam Tabel 5 sebagai berikut.

\section{Tabel 5.}

Pengaruh Langsung dan Pengaruh Tidak Langsung serta Pengaruh Total Hedonic Motivation (X), Shopping Enjoyment ( $\left.\mathrm{Y}_{1}\right)$, dan Impulse Buying $\left(\mathrm{Y}_{2}\right)$

\begin{tabular}{cccc}
\hline $\begin{array}{c}\text { Pengaruh } \\
\text { Variabel }\end{array}$ & $\begin{array}{c}\text { Pengaruh } \\
\text { Langsung }\end{array}$ & $\begin{array}{c}\text { Pengaruh Tidak Langsung Melalui Shopping } \\
\text { Enjoyment } \\
\left(\mathrm{Y}_{1}\right)(\beta 1 \times \beta 3)\end{array}$ & Pengaruh Total \\
\hline $\mathrm{X}_{1} \rightarrow \mathrm{Y}_{1}$ & 0,901 & - & 0,901 \\
& & - & 3773
\end{tabular}


$\mathrm{X}_{1} \rightarrow \mathrm{Y}_{2}$

0,360

0,339

0,699

$\mathrm{Y}_{1} \rightarrow \mathrm{Y}_{2}$

0,377

0,377

Sumber : Data diolah, 2018

Uji sobel merupakan alat analisis untuk menguji signifikansi dari hubungan tidak langsung antara variabel independen dengan variabel dependen yang dimediasi oleh variabel mediator. Uji Sobel dirumuskan dengan persamaan berikut dan dapat dihitung dengan menggunakan aplikasi Microsoft Excel 2007. Adapun langkah-langkah dalam pengujian variabel mediasi ( Uji sobel) antara lain:

Uji sobel dihitung dengan rumus dibawah ini:

$$
\begin{aligned}
& Z=\frac{a}{\sqrt{a^{2} s_{b}^{2}+b^{2} s_{u}^{2}+s_{u}^{2} s_{b}^{2}}} \\
& \operatorname{Sig}=(1-\operatorname{NORMDIST}(Z))+2))
\end{aligned}
$$

Keterangan:

$$
\begin{aligned}
& \mathrm{a}=0,901 \\
& \mathrm{~s}_{\mathrm{a}}=0,044 \\
& \mathrm{~b}=0,377 \\
& \mathrm{~s}_{\mathrm{b}}=0,161 \\
& Z=\frac{0,901 \cdot 0,377}{\sqrt{0,901^{2} 0,161^{2}+0,377^{2} 0,044^{2}+0,044^{2} 0,161^{2}}} \\
& Z=\frac{0,3397}{\sqrt{0,0210+0,0003+0,0001}} \\
& Z=\frac{0,3397}{0,146178} \\
& \mathrm{Z}=\mathbf{2 , 3 2 3}
\end{aligned}
$$

Tabel 6.

Hasil Uji Sobel

\begin{tabular}{cc}
\hline Nilai $\mathbf{Z}$ & Sig \\
\hline 2,323 & 0,000 \\
\hline Sumber: Data diolah, 2018 &
\end{tabular}


Hasil dari pengujian variabel mediasi sesuai dengan Tabel 6 yaitu shopping enjoyment didapatkan $\mathrm{Z}$ hitung sebesar 2,323>1,96 dengan tingkat signifikan sebesar $0,000<0,05$ yang berarti $\mathrm{H}_{0}$ ditolak dan $\mathrm{H}_{1}$ diterima yang berarti variabel shopping enjoyment dinilai secara signifikan memediasi secara parsial variabel hedonic motivation pada impulse buyingdi Stradivarius.

Pengujian hipotesis pada pengaruh hedonic motivationterhadap shopping enjoyment menunjukkan bahwa hedonic motivationsecara signifikan berpengaruh positif terhadapshopping enjoyment. Ini berarti semakin baik hedonic motivation konsumen maka semakin meningkatkan shopping enjoyment di Stradivarius Beachwalk.

Hasil penelitian ini mendukung temuan dari Konus et al. (2008) menyatakan bahwa hedonic motivation berhubungan dengan shopping enjoyment. Kim dan Youn (2008) dan Amel et al. (2014) menyatakan bahwa hedonic motivation mempengaruhi secara positif signifikan terhadap shopping enjoyment.

Pengujian hipotesis pada pengaruh hedonic motivationterhadap impulse buying menunjukkan bahwa hedonic motivationberpengaruh secara signifikan positif terhadap impulse buying. Ini berarti semakin baiknya hedonic motivation konsumen, maka akan meningkatkan impulse buying di Stradivarius Beachwalk. Hasil penelitian ini mendukung temuan dari penelitian terdahulu Suhartini et al. (2016) semakin konsumen merasakan hedonic motivation yang baik, maka akan menyebabkan tingkat impulse buying yang semakin tinggi. Kosyu et al. (2014), Amel et al. (2014), serta Mamuaya dan Aditya (2018) yang menunjukkan bahwa hedonic motivation berpengaruh positif dan signifikan terhadap impulse buying. 
Putu Cindy Clarista Darmaningrum, Peran Shopping Enjoyment...

Pengujian hipotesis pada pengaruh shopping enjoymentterhadap impulse buying menunjukkan bahwa shopping enjoymentsecara signifikan berpengaruh positif terhadap impulse buying. Ini berarti semakin baiknya shopping enjoyment konsumen, maka akan meningkatkan impulse buyingdi Stradivarius Beachwalk.

Hasil penelitian ini mendukung temuan dari penelitian terdahulu Gunadhi (2012), Amel et al. (2014), Badgaiyan dan Anshul (2014), Saad dan Metawie (2015) dan Purnasari dan Rastini (2018) menyatakan bahwa shopping enjoyment berpengaruh positif signifikan terhadap impulse buying.

Pengujian hipotesis pada peran shopping enjoyment dalam memediasi hedonic motivation terhadap impulse buying menunjukkan bahwa shopping enjoyment mampu memediasi pengaruh hedonic motivation terhadap impulse buying. Ini berarti shopping enjoyment memediasi pengaruh hedonic motivation terhadap impulse buying secara parsial. Dengan kata lain, shopping enjoyment memperkuat pengaruh hedonic motivation terhadap impulse buying.

Hasil penelitian ini mendukung temuan dari Kim dan Youn (2008) menyatakan bahwa hedonic motivation berpengaruh positif signifikan terhadap shopping enjoyment. Andryansyah dan Zainul (2018) menyatakan hedonic motives memiliki pengaruh signifikan terhadap impulse buying. Mohan et al. (2013) yang menyatakan bahwa shopping enjoyment berpengaruh positif signifikan terhadap impulse buying. Amel et al. (2014) menyatakan bahwa hedonic motivation berpengaruh positif dan signifikan terhadap impulse buying dengan mediasi shopping enjoyment. 
Implikasi dari penelitian ini mencakup dua hal yaitu, implikasi teoritis dan implikasi praktis yang menekankan pada manfaat nyata dari hasil penelitian ini untuk meningkatkan pembelian secara impulsif produk Stradivarius Beackwalk di Kabupaten Badung. Beberapa implikasi hasil penelitian ini adalah sebagai berikut:

Faktor yang berhubungan dengan impulse buying dalam peneltian ini adalah hedonic motivation dan shopping enjoyment. Implikasi teoritis yang berkaitan dengan impulse buying secara konsisten memperkuat teori sebelumnya bahwa hedonic motivation dan shopping enjoyment memengaruhi konsumen terhadap timbulnya impulse buying. Selain itu, variabel shopping enjoyment mampu menjadi pemediasi hedonic motivation dengan impulse buying. Semakin baik hedonic motivation yang dimiliki konsumen Stradivarius maka semakin dapat meningkatkan shopping enjoyment yang baik dan shopping enjoyment tersebut memiliki peranan penting dalam mempengaruhi impulse buying terhadap produk Stradivarius. Hal ini mendukung penelitian yang telah diungkapkan pada hipotesis penelitian, sehingga dapat disimpulkan bahwa penelitian ini mendukung serta memperjelas hubungan antara variabel shopping enjoyment, hedonic motivation, dan impulse buying.

Implikasi pertama didalam variabel hedonic motivation didapat hasil bahwa indikator konsumen lebih suka mencari tempat pembelanjaan yang menawarkan diskon dan harga yang murah. Menjadi indikator yang memiliki nilai skor tertinggi dibandingkan indikator lainnya, ini berarti bahwa Penawaran seperti diskon dan harga murah yang ditawarkan oleh Stradivarius Beachwalk di Kabupaten Badung, membuat konsumen memiliki rasa gembira dan senang saat 
membeli produk untuk memenuhi kepuasan tersendiri sehingga dapat dijadikan peluang bagi manajemen Stradivarius dalam meningkatkan penjualan dan kualitas produk Stradivarius agar memperkuat posisi produk Stradivarius Beachwalk di Kabupaten Badung di pasaran.

Implikasi yang kedua yaitu, didalam variabel shopping enjoyment didapatkan hasil bahwa indikator toko atau tempat berbelanja yang dikunjungi nyaman menjadi indikator yang memiliki nilai rata-rata tertinggi dibandingkan indikator lainnya, dan ini berarti bahwa konsumen merasa nyaman akan fasilitas dan suasana yang dirasakan di Stradivarius Beachwalk di Kabupaten Badung. Hal ini menjadikan modal yang sangat penting bagi Stradivarius Beachwalk di Kabupaten Badung untuk mempertahankan kenyamanan fasilitas yang disediakan demi menciptakan kenikmatan berbelanja konsumen.

Implikasi yang ketiga yaitu didalam variabel impulse buying didapatkan hasil bahwa indikator pembelian dipengaruhi penawaran menarik menjadi indikator yang memiliki nilai rata-rata tertinggi dibandingkan indikator lainnya, dan ini berarti bahwa penawaran yang ditawarkan Stradivarius Beachwalk di Kabupaten Badung membuat konsumen melakukan impulse buying dan hal ini menjadikan manajemen Stradivarius untuk selalu menawarkan penawaran menarik agar meningkatkan impulse buying di Stradivarius Beachwalk di Kabupaten Badung.

\section{SIMPULAN}

Variabel hedonic motivation berpengaruh positif dan signifikan terhadap shopping enjoyment. Hal tersebut menunjukkan semakin baik tingkat hedonic 
motivation konsumen maka semakin meningkatkan shopping enjoyment yang dirasakan konsumen di Stradivarius Beachwalk Kabupaten Badung.

Hedonic motivation berpengaruh positif dan signifikan impulse buying. Hal tersebut menunjukkan semakin baik tingkat hedonic motivation konsumen maka semakin meningkatkan impulse buying konsumen pada produk Stradivarius Beachwalk Kabupaten Badung.

Shoppig enjoyment berpengaruh positif dan signifikan terhadap impulse buying. Hal tersebut menunjukkan semakin baik tingkat shopping enjoyment yang dirasakan konsumen di Stradivarius maka semakin meningkatkan impulse buying konsumen pada produk Stradivarius Beachwalk Kabupaten Badung.

Shopping enjoyment mampu mediasi pengaruh hedonic motivation terhadap impulse buying. Hal tersebut menunjukkan bahwa shopping enjoyment memediasi pengaruh hedonic motivation terhadap impulse buying secara parsial. Dengan kata lain, shopping enjoyment memperkuat pengaruh hedonic motivation ke impulse buying.

Pihak Stradivarius hendaknya memanfaat hedonic motivation yang dimiliki konsumen dan shopping enjoyment yang dirasakan konsumen agar dapat meningkatkan penjualan melalui motivasi hedonis dan kenyamanan yang dirasakan konsumen.

Pihak Stradivarius hendaknya memanfaatkan hedonic motivation yang dimiliki konsumen, saat konsumen sudah memiliki rasa senang saat membeli sebuah produk semakin meningkatkan impulse buying. 
Pihak Stradivarius hendaknya meningkatkan dan memperhatikan kenyamanan suasana, fasilitas toko dan kualitas produk, dengan shopping enjoyment yang dirasakan konsumen semakin meningkatkan impulse buying.

Sebaiknya pihak Stradivarius memperhatikan kualitas produk yang ditawarkan dan kenyamanan suasana di Stradivarius agar konsumen dapat menghilanngkan stres dan meningkatkan impulse buying.

Bagi peneliti selanjutnya, diharapkan melakukan penelitian dengan lokasi dan sampel yang lebih luas. Pada masa mendatang juga perlu untuk menggunakan variabel-variabel yang lain seperti store environment, shopping lifestyle, dan emosi positif sehingga dapat memperkaya informasi yang diperoleh.

\section{REFERENSI}

Amel, G., Maachou, D.E.K., dan Elyas, S. (2014). Exploring women motivations toward impulse buying behavior in Algeria. Romanian Journal of Marketing. Vol. 2, No. 1, pp. 30-37.

Andryansyah, M. and Arifin, Z., (2018). Pengaruh hedonic motives terhadap shopping lifestyle dan impulse buying (Survei pada Konsumen Hypermart Malang Town Square yang melakukan pembelian tidak terencana). Jurnal Administrasi Bisnis, Vol. 57, No. 1, pp. 111-118.

Badgaiyan, A.J. dan Anshul Verma. (2014). Intrinsic factors affecting impulsive buying behavior Evidence from India. Journal of Retailing and consumer services. Vol. 2, No. 4, pp.537-549.

Desman, F.N., Yulihar, M., dan Zeshasina, R. (2018). Pengaruh Gaya Hidup, Store Atmosphere, Dan Motivasi Hedonis Terhadap Imuplsive Buying Konsumen May17 Distro Padang. E-jurnal Bunghatta. Vol. 9, No. 2, pp. $1-15$.

Deviana, D.N.P.S., dan Giantari, I.G.A.K. (2016). Pengaruh Shopping Lifestyle Dan Fashion Involvement Terhadap Impulse Buying Behaviour Masyarakat di Kota Denpasar. E-Jurnal Manajemen Universitas Udayana. Vol. 5, No.8, pp. 5264-5273. 
Gunadhi, N. (2012). Faktor-faktor yang mempengaruhi impulse buying pada Carrefour di Surabaya. Jurnal Ilmiah Mahasiswa Manajemen. Vol. 1, No. 4.

Kim, H.Y. dan Youn, K.K. (2008). Shopping enjoyment and store shopping modes: the moderating influence of chronic time pressure. Journal of Retailing and Consumer Services. Vol.15, No. 5, pp.410-419.

Kinasih, I.A.D., dan Jatra, I.M. Peran Emosi Positif Memediasi Pengaruh Fashion Involvement Dan Hedonic Consumption Tendency Terhadap Impulse Buying. E-Jurnal Manajemen Universitas Udayana. Vol.7, No.6, pp. 3258-3290.

Konus, U., Verhoef, P.C., dan Neslin, S.A. (2008). Multichannel shopper segments and their covariates. Journal of Retailing. Vol. 84, No. 4, pp.398-413.

Kosyu, D.A., Kadarisman, H., Yusri, Abdillah. (2014). Pengaruh Hedonic Shopping Motives Terhadap Shopping Lifestyle dan Impulse Buying (Survei pada Pelanggan Outlet Stradivarius di Galaxy Mall Surabaya). Jurnal Administrasi Bisnis. Vol.14, No.2, pp. 1-7.

Lestari, I.P. (2015). Pengaruh Hedonic Shopping Motivation Terhadap Impulse Buying Melalui Positive Emotion Customer Flashyshop. Jurnal Ilmu \& Riset Manajemen, Vol. 3, No.7, pp. 1-17.

Mamuaya, N.I., dan Aditya, P. (2018). The Influence Of Sales Promotion And Store Atmosphere On Hedonic Shopping Motivation And Consumer Impulse Buying In The Hypermart Of Manado City North Sulawesi. DeReMa (Development Research of Management). Jurnal Manajemen. Vol. 13, No. 1, pp. 83-99.

Manggiasih, F.P., Widiartanto., dan Prabawani, B. (2015). Pengaruh Discount, Merchandising, dan Hedonic Shopping Motives Terhadap Impulse Buying. Jurnal Ilmu Administrasi Bisnis. Vol.4, No.4, pp.164-174.

Mirandha, I., Iskandarsyah, M. (2018). Pengaruh Tampilan Etalase, Pendekatan Promosi, Gaya Hidup Berbelanja, Dan Karyawan Toko Terhadap Pembelian Impulsif Pada Pengunjung Hermes Palace Mall Kota Banda Aceh. Jurnal Ilmiah Mahasiswa Ekonomi Manajemen, Vol.2, No.3, pp. 108-125.

Mohan, G., Sivakumaran, B., dan Sharma, P. (2013). Impact of store environment on impulse buying behavior. European Journal of Marketing. Vol. 47, No.10, pp. 1711-1732. 
Naentiana, P.V. dan Setiawan, P.Y. (2014). Peran positive emotion dalam memediasi pengaruh hedonic shopping value terhadap impulse buying. $E$ Jurnal Manajemen Unud. Vol. 3, No. 8, pp. 2314-2332.

Oktafiana, S. dan Indriastuti, H. (2018). Membangun motivasi hedonic shopping dan store atmosphere terhadap impulse buying pada konsumen matahari departement store mall plaza mulia samarinda. In Prosiding SNMEB (Seminar Nasional Manajemen dan Ekonomi Bisnis). Vol. 1, pp. 414-421.

Purnasari, A.C. dan Rastini, N.M., (2018). Peran Kenikmatan Berbelanja Dalam Memediasi Kepribadian Terhadap Impulsive Buying. INOBIS: Jurnal Inovasi Bisnis dan Manajemen Indonesia. Vol. 1, No. 3, pp.329-342.

Purnomo, H., dan Riani, L.P. (2018). Analisis Hedonic Shopping Motives Terhadap Impulse Buying Toko Daring pada Masyarakat Kota Kediri. Ekspektra: Jurnal Bisnis dan Manajemen. Vol. 2, No.1, pp. 6888.

Putri, C.S. (2017). Pengaruh Media Sosial terhadap Keputusan Pembelian Konsumen Cherie Melalui Minat Beli. PERFORMA. Vol. 1, No.5. pp.594-603.

Rahayu, Y. (2017). Perilaku Belanja Impulsif Pengunjung Mall di Kota Bandung. Jurnal EKUBIS. Vol. 1, No. 2, pp. 20-30.

Rohman, F. (2009). Peran Nilai Hedonik Konsumsi dan Reaksi Impulsif sebagai Mediasi Pengaruh Faktor Situasional terhadap Keputusan Pembelian Impulsif di Butik Kota Malang. Jurnal Aplikasi Manajemen. Vol. 7, No. 2, pp. 251-261.

Saad, M. dan Metawie, M. (2015). Store environment, personality factors and impulse buying behavior in Egypt: The mediating roles of shop enjoyment and impulse buying tendencies. Journal of Business and Management Sciences. Vol. 3, No.2, pp. 69-77.

Salman, Mehrukh. (2014). Factors Influencing Impulse Buying of Sports Team Merchandise in Developing Country: An Empirical Investigation. Pakistan Journal of Commerce and Social Sciences. Vol. 8, No. 1, pp.185-200.

Sampurno, T.P. dan Winarso. (2015). Pengaruh Motivasi Hedonis, Browsing dan Gaya Belanja Terhadap Pembelian Impulsif Pada Toko Online Shop (Studi Pada Mahasiswa Universitas Muhammadiyah Yogyakarta). Jurnal Manajemen Bisnis. Vol. 6, No.1, pp.255-270. 
Sari, D.A.T. dan Alit, Suryani. (2014). Pengaruh Merchandising, Promosi Dan Atmosfir Toko Terhadap Impulse buying. Jurnal Manjemen. Vol. 3, No. 4, pp. 851-867.

Setyningrum, F.Y., Arifin, Z., dan Yulianto, E. (2016). Pengaruh Hedonic Motives Terhadap Shopping Lifestyle Dan Impulse Buying (Survei Pada Konsumen Superindo Supermarket Yang Melakukan Impulse Buying). Jurnal Administrasi Bisnis. Vol. 37, No.7, pp.97-104.

Suhartini, Y.I., Rodhiyah, R. dan Listyorini, S. (2016). Pengaruh Shopping Lifetyle, Fashion Involvement, dan Hedonic Shopping Motivation Terhadap Impulse Buying. Jurnal Ilmu Administrasi Bisnis. Vol. 5, No.1, pp.1-10.

Tambunan, S. dan Handayani, W. (2017). Minat Beli Ulang Kartu Perdana Nomor Cantik Simpati (Studi Dicomtech Shop Surabaya). Manajemen Bisnis$M E B I S$, Vol. 1, No.1, pp. 85-92.

Temaja, I.K.W.B., Rahanatha, G.B., dan Yasa, N.N.K. (2015). Pengaruh Fashion Involvement, Atmosfer Toko Dan Promosi Penjualan Terhadap Impulse Buying Pada Matahari Department Store Di Kota Denpasar. E-Jurnal Manajemen Universitas Udayana. Vol.4, No.6, pp. 1466-1482.

Tjantoko, L.E. (2015). Analisa Pengaruh Promosi dan Hedonic Motivation Terhadap Impulse Buying di Ron's Laboratory Galaxy Mall Surabaya. Jurnal Strategi Pemasaran, Vol. 3, No.1, pp.1-7.

Utami, Christina W. (2010). Manajemen Ritel, Strategi dan Implementasi Operasional Bisnis Ritel Modern di Indonesia. Jakarta: Salemba Empat.

Wibawa, B.M. dan Geodita, W.B. (2018). Analisis Model Struktural FaktorFaktor Pembentuk Fashion-Oriented Impulse Buying Produk Ritel Fashion Berdasarkan Sudut Pandang Konsumen Usia Remaja [Structural Model Analysis of Fashion-Oriented Impulse Buying of Retail Products Based on the Teenage Customer's Perspective. DeReMa (Development Research of Management). Jurnal Manajemen. Vol.13, No.1, pp.55-82.

Wiguna, A.A.I.N., dan Nurcaya, I.N. (2013). Pengaruh Fashion Involvement, Kualitas Produk dan Kewajaran Harga terhadap Impulse Buying. Bali. Jurnal fakultas Ekonomi dan Bisnis Universitas Udayana. Vol. 3, No. 12, pp. $3695-370$ 